\title{
Sex ratios and sex-biased infection behaviour in the entomopathogenic nematode genus Steinernema
}

\author{
Mohamed A.M. Alsaiyah, Lemma Ebssa ${ }^{1}$, Annemie Zenner, Kathryn M. O'Callaghan, Christine T. Griffin * \\ Department of Biology, National University of Ireland, Maynooth, Co. Kildare, Ireland
}

\section{A R T I C L E I N F O}

\section{Article history:}

Received 28 July 2008

Received in revised form 7 November 2008

Accepted 10 November 2008

\section{Keywords:}

Sex ratio

Male colonisation

Female-biased

Entomopathogenic nematode

Steinernema species

Nematoda

\begin{abstract}
A B S T R A C T
In experimentally infected insects, the sex ratio of first generation nematodes of five species of Steinernema was female-biased (male proportion 0.35-0.47). There was a similar female bias when the worms developed in vitro (0.37-0.44), indicating that the bias in these species is not due to a lower rate of infection by male infective juveniles (IJs). Experimental conditions influenced the proportion of males establishing in insects, indicating that male and female IJs differ in their behaviour. However, there was no evidence that males are the colonising sex in any species, contrary to what has previously been proposed. Time of emergence from the host in which the nematodes had developed influenced sex ratios in experimental infections. In three species (Steinernema longicaudum, Steinernema glaseri and Steinernema kraussei), early emerged nematodes had a higher proportion of males than those that emerged later, with the reverse trend for Steinernema carpocapsae and Steinernema feltiae. In a more detailed in vitro study of S. longicau$d u m$, the proportion of males was similar whether or not the nematodes passed through the developmentally arrested IJ stage, indicating that the female bias is not due to failure of males to exit this stage. The sex ratio in vitro was independent of survival rate from juvenile to adult, and was female-biased even when all juveniles developed, indicating that the bias is not explained by failure of males to develop to adults. The female-biased sex ratio characteristic of Steinernema populations appears to be present from at least the early juvenile stage. We hypothesise that the observed female bias is the population optimal sex ratio, a response to cycles of local mate competition experienced by nematodes reproducing within insect hosts interspersed with periods of outbreeding with less closely related worms following dispersal.
\end{abstract}

๔ 2008 Australian Society for Parasitology Inc. Published by Elsevier Ltd. All rights reserved.

\section{Introduction}

The sex ratio of acanthocephalan and nematode parasites is frequently biased towards females in both natural and experimental infections (Poulin, 1997), while that of schistosomes is typically male-biased (Mone and Boissier, 2004). The primary sex ratio of animals is expected to be balanced (Fisher, 1930) but later events such as differential survival and infection rates may result in biased sex ratios of parasites within hosts. Early mortality of males contributes to the female-biased sex ratio seen in many helminth parasites of vertebrates (Roche and Patrzek, 1966; Stien et al., 2005) while differential invasion rates of cercariae destined to be male or female contributes to the male-biased sex ratio of schistosomes (Boissier and Mone, 2000). Different behaviour of male and female infective stages has received little attention in parasitic nematodes, apart from the entomopathogenic nematodes Steinernema spp. Several studies have explicitly addressed the possibility

\footnotetext{
* Corresponding author. Tel.: +3531708 4841; fax: +35317084845.

E-mail address: christine.griffin@nuim.ie (C.T. Griffin).

1 Present address: Department of Entomology, Rutgers, The State University of New Jersey, NJ, USA.
}

that Steinernema infective juveniles (IJs) that are destined to be male and female differ with respect to dispersal and/or infection behaviour, affecting the within host sex ratio (Grewal et al., 1993; Lewis and Gaugler, 1994; Bohan and Hominick, 1997; Stuart et al., 1998; Fujimoto et al., 2007).

Steinernema spp. (Rhabditida: Steinernematidae) are parasites of a broad range of insects. Unlike most parasites they kill their host, with the aid of their associated symbiotic bacteria, Xenorhabdus spp. (Kaya and Gaugler, 1993). The life cycle is direct: IJs actively invade living insects and release their bacteria in the haemocoel, resulting in death of the host, often within $48 \mathrm{~h}$. Sex is chromosomally determined (Poinar, 1967). IJs develop to amphimictic adults which reproduce within the host cadaver. There can be up to three generations within a host, depending on resources (Wang and Bedding, 1996). The Steinernema life cycle includes two developmental pathways: juveniles develop directly to adults within a host cadaver as long as conditions are favourable, but in less favourable conditions (generally believed to be due to crowding and resource depletion (san-Blas et al., 2008)), developmentally arrested IJs are formed which leave the cadaver to search for another host. IJs may develop from eggs laid by generations under poor conditions such as a crowded cadaver, but may also develop 
in each generation from eggs which hatch within the mother i.e., in response to locally crowded conditions (Baliadi et al., 2004). The short life cycle, ready availability of naïve hosts and diversity of species make Steinernema an attractive model for addressing many biological questions (Stock, 2005).

Grewal et al. (1993) reported that male IJs of four species of Steinernema (Steinernema glaseri, Steinernema carpocapsae, Steinernema scapterisci and Steinernema anomali, but not Steinernema feltiae) disperse, locate and establish in distant live hosts before females, and proposed that males of these species are colonisers, invading the host before females and making the infected host more attractive to female IJs. This male colonisation hypothesis was not supported by a later study on S. glaseri (Stuart et al., 1998) and has remained controversial (Lewis et al., 2006). In contrast, Bohan and Hominick (1997) reported that female S. feltiae IJs invaded insect hosts before males, leading to a markedly femalebiased sex ratio during the initial phase of the infection, but the sex ratio became balanced as the infection progressed. Earlier arrival at the breeding area by one sex or the other is common across animal taxa, and protandry, where males arrive at the breeding site earlier than females, is the more common form of sex-biased arrival timing (Morbey and Ydenberg, 2001). Although its adaptive significance is not well understood, protandry is common in arthropods, birds and other taxa (Morbey and Ydenberg, 2001). Protandry may result if males either develop to adults earlier or disperse to the breeding site earlier, on average, than females. Both forms of protandry have been reported for species of Steinernema; early dispersal of males from a given cohort of IJs (Grewal et al., 1993) and early emergence of male IJs from the host (Lewis and Gaugler, 1994; Fujimoto et al., 2007). Lewis and Gaugler (1994) reported that in S. glaseri (but not $S$. carpocapsae) IJs that will develop into adult males emerge from their natal cadavers before those that develop into females. They proposed that protandrous emergence is more likely to be adaptive in species such as S. glaseri which employ "cruising" as a strategy to seek their hosts, rather than "ambush" foragers as is the case with $S$. carpocapsae. Since ambush foragers rely on host movement it is unlikely that either sex would find a host before the other. However, Fujimoto et al. (2007) reported earlier emergence of male IJs in S. carpocapsae also. There are thus two behavioural traits that may lead to a biased sex ratio in experimental infections of Steinernema: a greater tendency of one or the other sex within a population of infective juveniles to infect (Grewal et al., 1993; Bohan and Hominick, 1997), and a skewed population made up of unequal numbers of males and females due to differential time of emergence from a host.

We report here a systematic study of Steinernema sex ratios in vivo in experimentally infected hosts and in vitro. The first objective was to look for evidence of differential dispersal or infection behaviour of male and female Steinernema juveniles as a contributory factor to skewed sex ratios of first generation adults. For this, we used the approach of Grewal et al. (1993), comparing the sex ratio of nematodes established in near and distant hosts (using filter paper and sand assays, respectively), based on the assumption that distant hosts should contain a higher proportion of the dispersing sex. We also include a sequence of exposure times in the sand assay, based on the assumption that if one sex invades before the other, the sex ratio should initially be skewed, but should then stabilise (Bohan and Hominick, 1997; Stuart et al., 1998). Experiments were repeated using two cohorts of IJs, early and later-emerging ones, as time of emergence from the natal cadaver is reported to influence sex-biased infection patterns (Lewis and Gaugler, 1994; Rolston et al., 2006; Fujimoto et al., 2007). For comparison, IJs were also reared in vitro to eliminate the effects of infection and dispersal behaviour on sex ratio. The second objective was to examine the role of factors other than IJ behaviour in influencing adult sex ratio, such as differential recovery rates of
Table 1

Species and strains of Steinernema used in the experiments together with their foraging strategies and their phylogenetic relationships.

\begin{tabular}{lll}
\hline Species and strain & Foraging strategy $^{\mathrm{a}}$ & Clade $^{\mathrm{b}}$ \\
\hline Steinernema carpocapsae All & Ambush & II \\
Steinernema glaseri NC1 & Cruise & V \\
Steinernema longicaudum CB2B & Cruise & V \\
Steinernema kraussei L137 & Cruise & III \\
Steinernema feltiae 4CFMO & Intermediate & III \\
\hline
\end{tabular}

a Campbell et al. (2003)

b Spiridonov et al. (2004) and Nadler et al. (2006).

males and females from the developmentally arrested IJ stage, or their survival to adult. This more detailed study was done on Steinernema longicaudum reared in vitro. All determinations of sex were made on adult worms, since IJs cannot easily be sexed. We include five species of Steinernema representing varied phylogenetic clades and foraging modes (Table 1).

\section{Materials and methods}

\subsection{Source and cultivation of nematodes}

Nematodes were cultured in larvae of Galleria mellonella (Lepidoptera: Pyralidae; the greater wax moth) using standard procedures (Woodring and Kaya, 1988). Culturing was at $20^{\circ} \mathrm{C}$ with the exception of Steinernema kraussei which was cultured at $15^{\circ} \mathrm{C}$. Cadavers were placed in White traps (10 insects per trap) from which the emerging IJs were harvested. Modified White traps, in which juveniles must climb up the side of a Petri dish before reaching the surrounding water (Woodring and Kaya, 1988) were used for S. glaseri and S. longicaudum. Modified traps suit species in which the nematodes emerge as pre-IJs. IJs that were harvested on the 1st day of emergence ("early emergers") and on the 10th day after emergence began ("late emergers") were used in experiments. Infective juveniles that emerged in the intervening period were discarded. For both standard and modified White traps, the day on which IJs entered the water of the trap was counted as the day of emergence, and in both cases reflects the departure of newly formed IJs from the vicinity of the source cadavers. Harvested IJs were washed three times by sedimentation, the concentration was adjusted to $2000 \mathrm{IJs} / \mathrm{ml}$, and the suspension was stored in tap water for 2 days at $9{ }^{\circ} \mathrm{C}$ except for the tropical species $S$. longicaudum which was stored at $20^{\circ} \mathrm{C}$.

\subsection{Experimental infections}

The experimental assay of Stuart et al. (1998) was adopted for this study. Nematodes were applied to the top of sand columns containing a wax moth larva at the bottom. For most species $80 \mathrm{ml}$ vials, forming sand columns $4 \mathrm{~cm}$ high and $2.5 \mathrm{~cm}$ diameter, were used. Since $S$. carpocapsae did not migrate through the $4 \mathrm{~cm}$ sand column, cells of a 24 multi-well plate, forming sand columns of $8 \mathrm{~mm}$ height and $5 \mathrm{~mm}$ diameter, were used for this species. Fine and coarse sand particles were removed by sieving over 150 and $450 \mu \mathrm{m}$ sieves, respectively. The sand was then sterilized at $120{ }^{\circ} \mathrm{C}$ for $24 \mathrm{~h}$. The moisture content of the sand was adjusted to $8 \% \mathrm{w} / \mathrm{w}$ using tap water. Early or late emerging IJs of one of the five Steinernema spp. at a concentration of $100 \mathrm{IJs}$ in $100 \mu \mathrm{l}$ tap water were added to a depression in the top of the sand surface and the columns were capped. Columns were incubated at $20^{\circ} \mathrm{C}$ except for $S$. kraussei which was incubated at $15^{\circ} \mathrm{C}$. The nematodes were allowed to migrate through the sand column for periods ranging from 4 to $48 \mathrm{~h}$, after which the insects were removed from the column, washed to remove adhering IJs and incubated at the 
assay temperature. Mortality was recorded daily. There were normally 10 replicate columns (vials or wells) per treatment but in some instances where low numbers were expected, 20 columns were used. Invasion of distant hosts (sand column) was compared with invasion into a host in close contact, on filter paper as in Grewal et al. (1993). Using the same nematode suspension as for the sand column assay, 10 insects were exposed to 1000 IJs (hence approximately 100 nematodes per insect) of each nematode species on filter paper lining a $9 \mathrm{~cm}$ diameter Petri dish and incubated at the assay temperature (Woodring and Kaya, 1988). In each experiment, early and late emerging nematodes were from the same group of 10 insect cadavers. A complete time course assay was run 2-4 times for each species using a different, freshly harvested, batch of nematodes in each assay (minimum: two full time course assays using, respectively, an early and late emergence cohort in each assay; see Table 2). Insect cadavers from both sand column and filter paper experiments were dissected 4-5 days after first exposure to nematodes. The number of male and female nematodes in each insect was counted, and taken to represent the number of IJs that had invaded and established in the insect during the exposure period, since $4-5$ days is too short a time for production of second generation worms. Numbers of insects and nematodes used in the analyses are given in Table 2 .

\subsection{Population sex ratio}

Since differential invasion rates of males and females into an insect may result in biased sex ratios, we reared nematodes from $\mathrm{IJ}$ in vitro in hanging drops of insect haemolymph. IJs were surface sterilised with hyamine and transferred to a hanging drop of G. mellonella haemolymph (Kaya and Stock, 1997), one nematode per drop. In response to the food signal provided by the haemolymph, IJs are expected to recover from the developmentally arrested stage and release their symbiotic bacteria into the medium. Within 2-4 days, the IJs had either recovered from the IJ stage and developed to first generation males and females, or failed to recover. Thus, 3-4 days after inoculation of the drops, the worms were scored as male, female or IJ that failed to develop. For S. longicaudum only, the number of males and females developing to adult without passage through the IJ stage was also recorded. In Steinernema spp., worms of the second and subsequent generations that begin development when conditions are favourable do not pass through the IJ stage and instead develop to adults within the natal host (Nguyen and Smart, 1992). To obtain the second generation, adults that had developed from IJs were paired and allowed to reproduce in the hanging drop. The resulting juveniles were then individually transferred to a fresh hanging drop of haemolymph that had been previously inoculated with bacteria-rich haemolymph from the parental drop. These second generation developmental (non-IJ) nematodes were allowed to develop and their sex was determined as for the first generation.

\subsection{Data analysis}

Data of experiments repeated over time were checked for variance homogeneity using the HOVTEST = LEVENE option of SAS 9.1 (SAS Institute, 2004) and pooled only when variance homogeneity could be assumed. To stabilise variance, data on number of nematodes $(x)$ and male proportion ( $p$, as number of males divided by total number of nematodes) per larva were transformed using $\sqrt{x+0.0001}$ and arcsine $(\sqrt{p+0.0001})$, respectively. Since variances were not homogenous across different treatment combinations, a heterogeneous variance structure was used in the PROC MIXED model in SAS (Littell et al., 1996). Thus, single and interaction effects of factors on number of nematodes and male proportion were analysed using the MIXED model procedure. Whenever two factors interacted significantly, levels of a given factor were compared at each level of the second factor; otherwise, data were pooled in case of non-significant interaction between factors. Since normal distribution of the data could not be assumed across every treatment combination, change in male proportion over time was assessed using a $2 \times \mathrm{k}$ contingency table. Male proportion difference between arenas (sand versus filter paper) was assessed using a non-parametric Wilcoxon test. The number of nematodes invading hosts at different times was compared using a non-parametric Holm procedure (Holm, 1979) by modelling the procedure in SAS. For sex ratio in the total population of nematodes under different conditions, a $2 \times 2 \chi^{2}$ test was used. To determine sex ratio deviation from 1:1 male to female, total numbers of male and female nematodes under a give treatment were tested using a 50:50 goodness-of-fit test in $\chi^{2}$. Association between the proportion of juveniles developing to adult and the proportion of adults that were male was explored using correlation analysis in SAS. Similarly, correlation analysis was used to report any association between male proportion and the total number of nematodes that invaded the host. For multiple comparisons in overall male proportion among different treatments, total number of males and females were subjected to $\chi^{2}$ test and alphas corresponding to the comparisons were adjusted according to the Bonferroni-Holm step down test (Zar, 1999). For all analyses $\alpha=0.05$ was used and non-transformed means ( \pm SEM) are reported.

\section{Table 2}

Total number of Galleria mellonella (G.m) larvae individually exposed to different Steinernema species for different exposure times in a sand column assay. The number of larvae infected by the nematodes and hence providing data points for analyses are indicated in parentheses. Also shown is the total number of nematodes (male and female; $N^{a}$ ) counted from all successfully infected larvae under a given treatment to generate sex ratio at the corresponding treatment.

\begin{tabular}{|c|c|c|c|c|c|c|c|c|c|c|}
\hline \multirow[t]{2}{*}{ Time (h) } & \multicolumn{2}{|c|}{ Steinernema carpocapsae } & \multicolumn{2}{|c|}{ Steinernema feltiae } & \multicolumn{2}{|c|}{ Steinernema glaseri } & \multicolumn{2}{|c|}{ Steinernema kraussei } & \multicolumn{2}{|c|}{ Steinernema longicaudum } \\
\hline & G.m & $N$ & G.m & $N$ & G.m & $N$ & G.m & $N$ & G.m & $N$ \\
\hline 4 & $60(54)$ & 262 & $20(8)$ & 15 & $30(0)$ & - & $20(0)$ & - & $40(2)$ & 7 \\
\hline 6 & $60(52)$ & 374 & $20(17)$ & 81 & $30(0)$ & - & $20(0)$ & - & $40(9)$ & 46 \\
\hline 8 & $60(55)$ & 566 & 20 (19) & 164 & $30(2)$ & 2 & $20(10)$ & 11 & $40(16)$ & 143 \\
\hline 10 & 20 (19) & 424 & $20(20)$ & 282 & $30(4)$ & 16 & $90(37)$ & 77 & $40(27)$ & 288 \\
\hline 20 & $40(36)$ & 1060 & $40(39)$ & 1490 & $30(15)$ & 450 & $40(40)$ & 452 & $120(115)$ & 2249 \\
\hline 24 & $20(19)$ & 861 & $20(20)$ & 906 & $30(18)$ & 548 & $40(39)$ & 742 & $40(39)$ & 1658 \\
\hline 48 & $20(17)$ & 834 & $20(17)$ & 752 & 30 (19) & 1029 & $40(38)$ & 798 & $40(34)$ & 1310 \\
\hline N1 & 2 & & 2 & & 3 & & 2 & & 4 & \\
\hline N2 & 1 & & 0 & & 0 & & 1 & & & \\
\hline
\end{tabular}

$\mathrm{N} 1$, number of full time courses using either early or late-emerged nematodes and 10 insects per treatment. For each full time course in sand, there was in addition a filter paper assay with 10 insects per treatment. 


\section{Results}

\subsection{Sex ratio}

3.1.1. Effect of exposure time on sex ratio in experimentally infected hosts (sand column assay)

If IJs of one sex disperse and enter insects before those of the other, then the sex ratio in the sand assay should be initially skewed, but should tend towards the fundamental sex ratio with longer exposure time as more of the slower sex arrive (Bohan and Hominick, 1997; Stuart et al., 1998). To assess the effect of exposure time on change in sex ratio, we carried out a separate contingency table analysis for each time course assay. Within a time course assay, the sex ratio (proportion of males) tended to remain constant irrespective of exposure time. Of the 13 full time course assays, the only significant difference in male proportion with exposure time was for $S$. kraussei early emergers $\left(\chi^{2}=\right.$ $4.271, \mathrm{df}=4, P=0.037)$. The proportion of males was higher at $10 \mathrm{~h}$ than at other times, but the number of nematodes was relatively low at that time period ( $n=39$ at $10 \mathrm{~h}$ ). When the assay was repeated two more times (omitting the early exposure times of $4-8 \mathrm{~h}$ at which there was no or little invasion), there was no difference in sex ratio between times in either assay $(P>0.05)$. In one of the three full assays conducted for $S$. glaseri late emerging nematodes, the effect of time on male proportion approached significance $\left(\chi^{2}=7.748, \mathrm{df}=3, P=0.052\right)$; here the trend was for the proportion of male nematodes to increase with time (Fig. 1).

\subsubsection{Effect of dispersal distance on sex ratio in experimentally} infected hosts: sand assay versus filter paper assay

If male IJs are more likely to disperse, then there should be a higher proportion of males within insects in the sand column assay, where dispersal is required, than in the filter paper assay where nematodes and insects are in close contact (Grewal et al., 1993). This was not found for any species; instead, the reverse was found for four of the five species tested (Fig. 2A and B). To compare sex ratio differences between assays (filter paper and sand), data from all exposure times for a given species in the sand assay were pooled. The nature of the assay (sand or filter paper) had a highly significant effect on the male proportion (Assay: $F_{1,1023}=34.97, P=<0.0001$, Table 3 ), but the effect was dependent on species and harvest (significant three-way interaction, Table 3 ). The male proportion was significantly higher in the filter paper than in the sand column assay only for the early harvest of $S$. kraussei $(P=0.0002)$ and $S$. longicaudum $(P=0.0013)$ and late harvest of $S$. glaseri $(P=0.0075)$ and $S$. longicaudum $(P=0.0039)$. The same trend was also observed for both early $(P=0.0648)$ and late $(P=0.0658)$ harvests of $S$. feltiae. On the other hand, the male proportion of $S$. carpocapsae did not differ between arenas for either harvests. The trend for higher male proportion in the filter paper assay than in the sand assay for all species except $S$. carpocapsae is also evident from the contingency table analysis on pooled data in Table 4.

\subsubsection{Effect of emergence time from natal cadaver on sex ratio in target insect}

Emergence time had a significant effect on sex ratio in the target insect (emergence: $F_{1,1023}=5.57, P=0.0185$, Table 3 ), but the effect depended on species and assay type (significant three-way interaction, Table 3). For S. carpocapsae and S. feltiae, the male proportion in target cadavers tended to be higher for later emerged than for early emerged nematodes, while for the other three species the male proportion was higher for the early emerged cohort (Fig. 2A and B). Trends in sex ratio between early and late emerging nematodes were similar whether the experimental infection was in sand or filter paper (emergence $\times$ assay term not significant, Table 3) but for each species the difference was significant in only one of the two assay types (sand for S. feltiae, S. glaseri and S. longicaudum; filter paper for S. carpocapsae and S. kraussei) (Fig. 2A and $\mathrm{B})$.

\subsubsection{Population sex ratio: hanging drop}

Similar to infection experiments, the sex ratio of nematodes developing from IJ in hanging drops was female-biased for each of the five species: the male proportion ranged from 0.37 (S. kraussei) to 0.44 (S. glaseri).

A more detailed examination of sex ratio was performed for $S$. longicaudum only. As for worms that developed from IJ, the sex ratio of second generation worms was also female-biased $(0.47$; $n=891)$ and deviated from the expected $1: 1\left(n=891 ; \chi^{2}=4.18\right.$, $P=0.0410$ ). The male proportion did not differ between the adults that developed from IJs (first generation) and those that developed without passage through the IJ stage (second generation juveniles) $\left(\chi^{2}=2.95, P=0.0857\right)$. Assessments of sex ratio were carried out on several occasions on different batches of nematodes ( 27 batches of first generation and 14 of second generation worms). The proportion of S. longicaudum IJs and second generation juveniles that developed to adult in vitro varied considerably across batches, ranging from $10 \%$ to $100 \%$ (Fig. 3). However, the male proportion did not significantly correlate $(r=-0.015, P=0.9184$, Fig. 3$)$ with the percentage of juveniles developing to adulthood. The average male proportions of the nematodes in the hanging drops across batches were $0.42( \pm 0.02)$ and $0.46( \pm 0.03)$ in first and second generation, respectively.

For S. longicaudum developing from IJ in hanging drops, nematodes that had emerged from the natal cadaver at different times did not differ significantly in their sex ratio $(t=0.23, P=0.8158)$. Male proportions of adults developing from early emerged $(n=7)$ versus late-emerged $(n=30)$ IJs were $0.43(\mathrm{SE}=0.044)$ and 0.42 $(\mathrm{SE}=0.023)$, respectively.

\subsubsection{Overall sex ratio}

Whether assessed in insects or following development from IJ in hanging drops, the proportion of males in the population was always less than $50 \%$ (Table 4). Using a goodness-of-fit $\chi^{2}$ test, the sex ratio in the population that developed from IJs in hanging drops deviated significantly from $1: 1\left(\chi^{2}\right.$ test, $\left.P<0.05\right)$ for each species except S. glaseri: S. longicaudum $\left(n=2392 ; \chi^{2}=43.89\right.$, $P<0.0001)$, S. carpocapsae $\left(n=383 ; \chi^{2}=6.79, P=0.0092\right)$, S. feltiae $\left(n=327 ; \chi^{2}=6.76, \quad P=0.0093\right)$ and $S$. kraussei $(n=298$; $\left.\chi^{2}=21.48, P<0.0001\right)$, S. glaseri $\left(n=180 ; \chi^{2}=2.69, P=0.1011\right)$ (Table 4).

For nematodes developing in insects, the deviation from the 1:1 was tested separately for early and late-emerged cohorts. Except for early emerged $S$. glaseri $\left(n=458 ; \chi^{2}=0.43, P=0.5130\right)$ and S. kraussei $\left(n=1,208 ; \chi^{2}=0.27, P=0.6045\right)$ in filter paper infection, sex ratios of all species and emergence cohorts in both sand column and filter paper assays deviated significantly from $1: 1$.

There was no marked difference in sex ratio between IJs developing in vitro or in insect hosts. For S. carpocapsae there was no significant difference in the male proportion assessed in the three ways (in vitro, in sand, or filter paper assays) (Table 4). For each of the other species there was a higher male proportion in the filter paper assay than in the sand assay, but in each species the in vitro male proportion was statistically indistinguishable from one or other of the insect assays (filter paper for S. feltiae and S. glaseri, sand assay for S. longicaudum and S. kraussei).

The male proportion was independent of the total number of nematodes found in experimentally infected hosts, except for a 

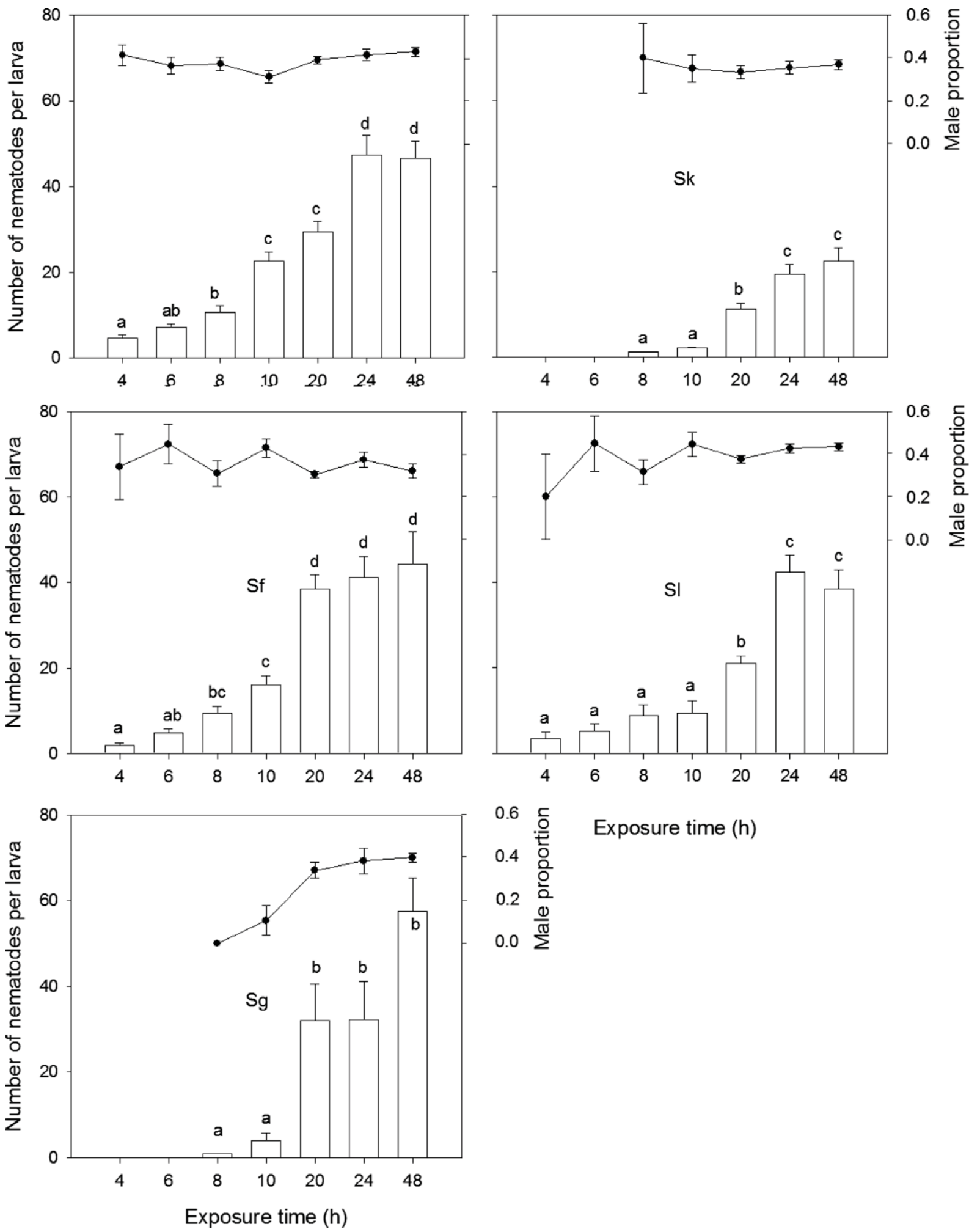

Fig. 1. Number $( \pm$ SEM) of nematodes per larva (bar chart) and male proportion (line chart) after exposure of a wax moth larva to 100 infective juveniles of Steinernema carpocapsae (Sc), Steinernema glaseri (Sg), Steinernema longicaudum (SI), Steinernema kraussei (Sk) or Steinernema feltiae (Sf) for different times in a sand column. Since exposure time and time of emergence of the nematodes from cadavers in the in vivo culturing did not interact significantly for both number of nematodes $\left(F_{6,799}=0.90\right.$, $P=0.4975)$ and male proportions $\left(F_{6,799}=1.14, P=0.3380\right)$, data from both emerging times were pooled for a given exposure time. For a given species, values accompanied by the same letter do not differ significantly (Holm test).

positive correlation in late emerging $S$. carpocapsae in both sand column $(r=0.20, P=0.0332)$ and filter paper assays $(r=0.69$, $P=0.0015)$ and in late emerging $S$. glaseri in sand column assay $(r=0.40, P=0.0206)$.
In each of the infection assays, S. feltiae was one of the two species with the lowest male proportion (together with S. kraussei in the sand assay and with $S$. carpocapsae in the filter paper assay), but this pattern was not repeated in vitro (Table 4 ). 

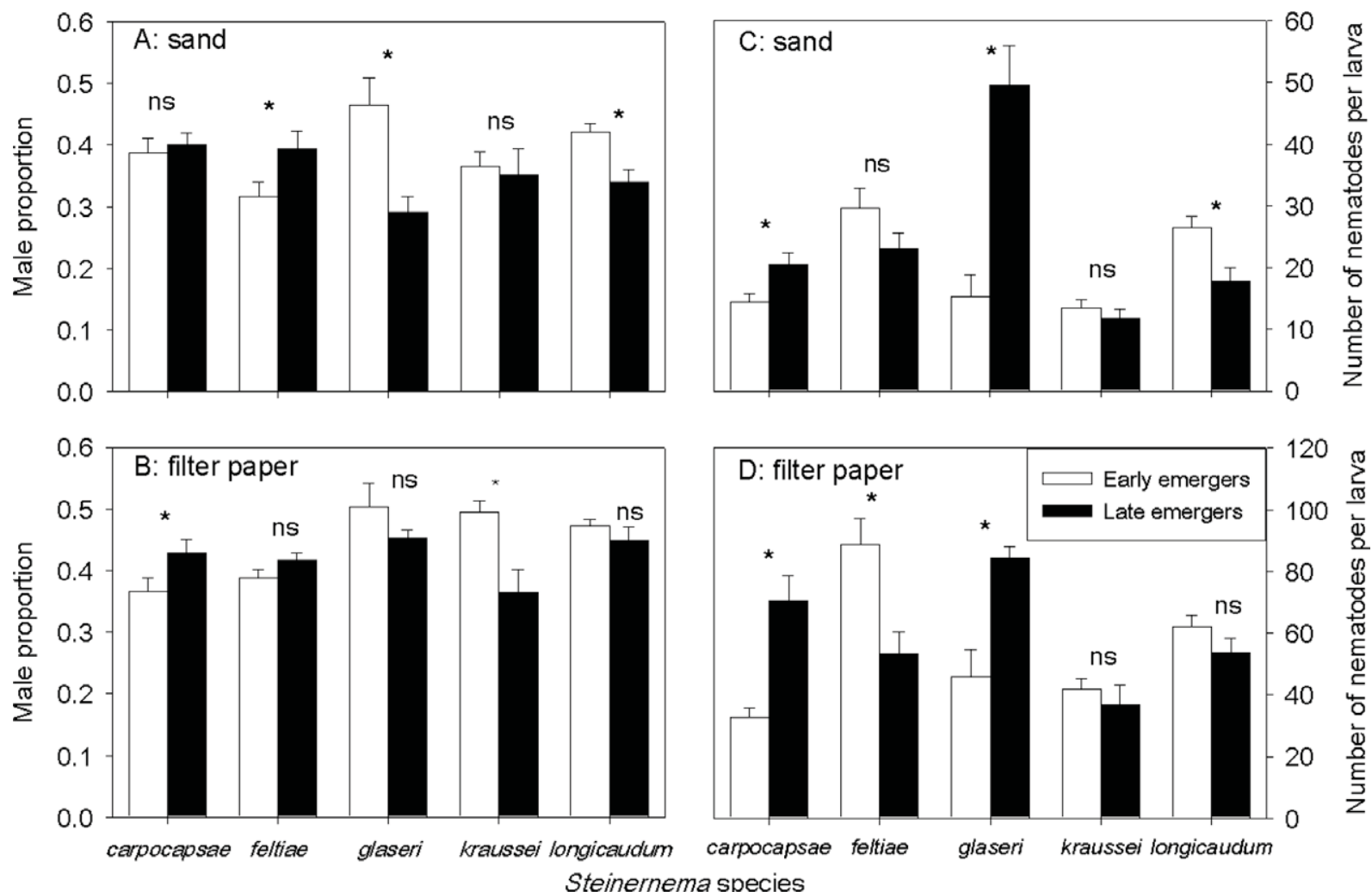

Fig. 2. Mean ( \pm SEM) proportion of males (A and B) and number of nematodes per Galleria mellonella larva ( $C$ and $D)$ of Steinernema spp. in sand (A and C) and filter paper (B and D) assays. Nematodes emerging early (day 1 ) or late (day 10) from host cadavers in which they had developed were used in the experimental infections of $G$. mellonella in sand or filter paper assays. Data for a given emergence cohort (early or late) were pooled from different exposure times in the sand assay as the two factors did not interact significantly (see text). * denotes significant difference between early and late emergers for a given species; ns, non-significant (Wilcoxon test).

Table 3

Main and interaction effects of nematode species, emergence cohort (Emergence) and assay type (in sand column or filter paper arena) on the number of nematodes infecting Galleria mellonella larvae and on sex ratio of nematodes established in the larvae.

\begin{tabular}{|c|c|c|c|c|c|}
\hline \multirow[t]{2}{*}{ Source of variation } & \multirow[t]{2}{*}{ df } & \multicolumn{2}{|c|}{ Number of nematodes } & \multicolumn{2}{|c|}{ Sex ratio } \\
\hline & & $F$ & $P$ & $F$ & $P$ \\
\hline Assay & 1 & 415.01 & $<0.0001$ & 34.97 & $<0.0001$ \\
\hline Emergence & 1 & 5.96 & 0.0148 & 5.57 & 0.0185 \\
\hline Species & 4 & 16.43 & $<0.0001$ & 2.21 & 0.0657 \\
\hline Assay $\times$ species & 4 & 0.48 & 0.7510 & 1.97 & 0.0974 \\
\hline Emergence $\times$ species & 4 & 20.51 & $<0.0001$ & 5.92 & 0.0001 \\
\hline Emergence $\times$ assay & 1 & 0.15 & 0.7018 & 0.12 & 0.7255 \\
\hline Emergence $\times$ assay $\times$ species & 4 & 3.32 & 0.0103 & 2.61 & 0.0342 \\
\hline Error & 1023 & & & & \\
\hline
\end{tabular}

Table 4

Overall proportion of males (total number of adults examined) of Steinernema spp. in Galleria mellonella infected in sand column or filter paper assays, or that developed in vitro in insect haemolymph. Male proportions followed by the same letter do not differ significantly; lower case letters, within column; upper case letters, within row. For treatment comparisons, $P$-values from $\chi^{2}$ test were adjusted using BonferroniHolm step down approach.

\begin{tabular}{llll}
\hline Species & Sand & Filter paper & Haemolymph \\
\hline Steinernema carpocapsae & $0.42(4136)$ b A & $0.43(1887)$ a A & $0.43(383)$ ab A \\
Steinernema feltiae & $0.35(3482)$ a A & $0.40(1135)$ a B & $0.43(327)$ ab B \\
Steinernema longicaudum & $0.42(5435)$ b A & $0.47(3979)$ b B & $0.43(2392)$ ab A \\
Steinernema glaseri & $0.35(1992)$ a A & $0.47(1132)$ b B & $0.44(180)$ b B \\
Steinernema kraussei & $0.40(2066)$ b A & $0.46(1575)$ b B & $0.37(298)$ a A \\
\hline
\end{tabular}

\subsection{Infection rate}

In the filter paper assay, virtually all (>99\%) of the exposed insects were killed by nematodes. In the sand assay, insect mortality increased with time of exposure, reaching close to $90 \%$ after $20 \mathrm{~h}$ exposure time. The proportion of nematodes established in the insects was used as a measure of infectivity.

In the sand column assay, the number of nematodes per insect increased with increasing exposure time, reaching $20 \mathrm{~S}$. kraussei and 40-60 nematodes for other species after $48 \mathrm{~h}$ exposure time (Fig. 1). The number of nematodes per insect in this assay differed significantly $(P<0.0001)$ depending on nematode species, length of exposure, and time of emergence, with significant interactions between species and emergence $\left(F_{4,799}=21.46, P<0.0001\right)$ and species and exposure time $\left(F_{20,799}=3.266, P<0.0001\right)$ but not for emergence and time $\left(F_{6,799}=0.9, P=0.495\right)$ and the three-way $\left(F_{15,799}=1.45, P=0.1183\right)$. For all exposure times, infection by $S$. kraussei was lower than all the other species (except for $S$. glaseri at shorter exposure times) (Fig. 1).

To compare infection rates across the two assays, data from all time points in the sand assay were pooled. Assay type, emergence cohort and species all significantly affected infection rates, and there was a significant three-way interaction between the three factors (Table 3). Infection rates tended to be higher in filter paper than in sand (Fig. 2C and D). For S. carpocapsae and S. glaseri, the number of late-emerged nematodes colonising hosts was higher than the number of early emerged nematodes, and the difference was significant in both assays (Fig. 2C and D). For S. feltiae and S. longicaudum more early-emerging than later-emerging nematodes infected (significant in filter paper or sand assay, respectively) 


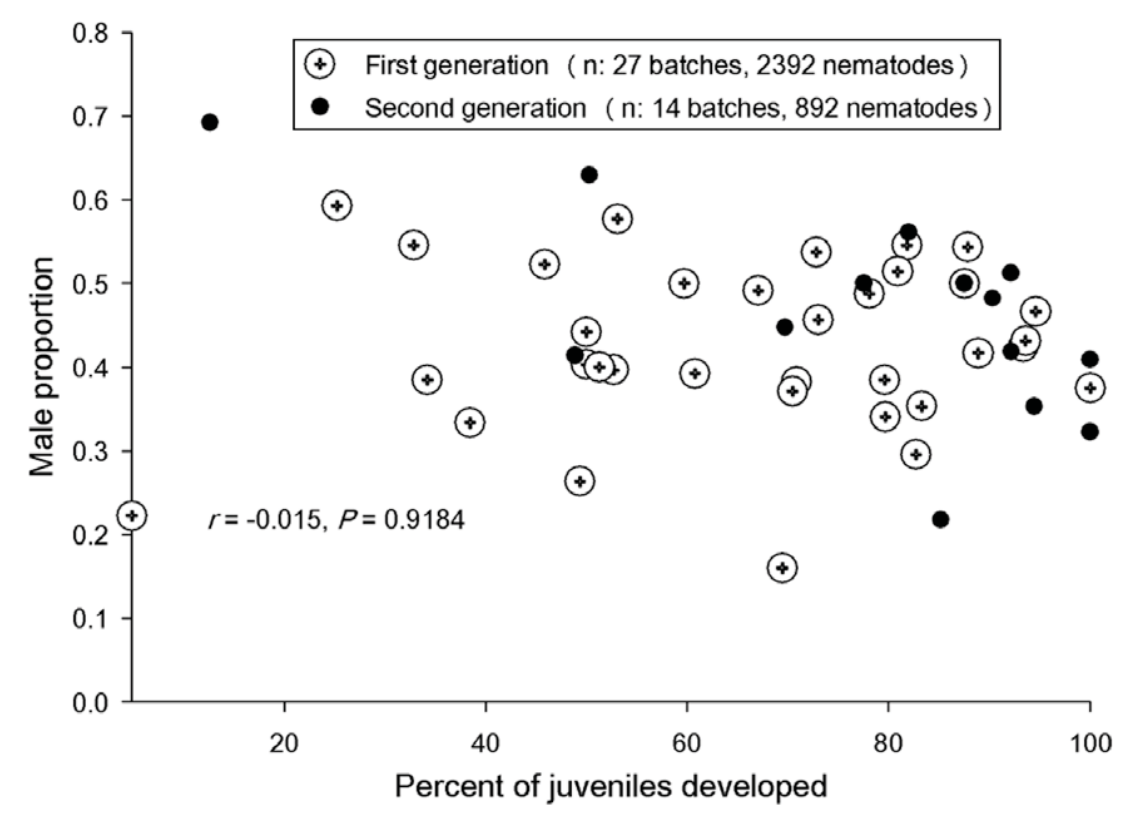

Fig. 3. Correlation of male proportion and success in development of juveniles to adults in first and second generations of Steinernema longicaudum in hanging drops of haemolymph. First generation adults developed from infective juveniles while second generation adults were offspring of the first generation of nematodes and did not pass through the infective juvenile stage. Each point represents a batch of nematodes (24-245 nematodes per batch) in which juveniles of the same batch were individually inoculated into separate haemolymph drops on the same day. The two generations did not differ in male proportion $(t=1.14$, $\mathrm{df}=49, P=0.2615)$ and success of juvenile development $(t=1.62, \mathrm{df}=49, P=0.1110)$ and hence data from both generations were pooled to run the correlation analysis.

while for $S$. kraussei there was no difference in infection rate between emergence cohorts (Fig. 2C and D).

\section{Discussion}

The most striking finding of our study is the overall female bias in experimentally infected hosts for all five species of Steinernema and under all test conditions. The male proportion never reached $50 \%$ (except with S. glaseri for early emergers on filter paper where it was $50.2 \%$ ), and in most cases there was a significant deviation from equality of the sexes. The sex ratios of nematode parasites tend to be female-biased (Poulin, 1997). With the notable exception of Steinernema hermaphroditum where males comprise less than $6 \%$ of the population (Griffin et al., 2001), a similarly slight female bias (typically 60\% female) has frequently been recorded in experimental infections of Steinernema spp. (Danilov, 1976; Nguyen and Smart, 1992; Selvan et al., 1993; Campbell and Kaya, 2002; Cabanillas, 2003; Mitani et al., 2004) (Table 5), including the close contact assay of Grewal et al. (1993). The preponderance of females found in experimentally infected hosts was seen also when Steinernema spp. infective juveniles were reared in vitro, showing that the female bias within hosts cannot be explained by a higher infection rate of females. However, there was some variation in sex ratio depending on the experimental infection conditions, indicating that the behaviour of IJs destined to become male and female may differ.

The results of our experiments provide little support for protandry in any species of Steinernema. The main hypothesis under test was that, within a given cohort of IJs, those that are destined to become male disperse and invade insect hosts before females. Grewal et al. (1993) reported that in S. carpocapsae, S. anomali, S. scapterisci, and S. glaseri, $58-100 \%$ of nematodes that invaded hosts located $10 \mathrm{~cm}$ away from the point of nematode application were male, while the sex ratio in hosts in close contact was female-biased. They proposed that this difference reflected a greater dispersal tendency of males than of females, and this was supported by finding that IJs that were first to reach hosts on agar plates containing a high proportion of males. They proposed that in those four species, males are risk takers. Using a similar infection protocol to Grewal et al. (1993) (sand column versus filter paper assays), we found a lower proportion of males in hosts that were invaded following migration in the sand assay, which is the reverse of what is predicted if males have a higher dispersal tendency than females.

Stuart et al. (1998) proposed that conclusions about differences in the speed with which males and females invade insects require that the duration of exposure is varied and changes in the sex ratio in hosts exposed for different times are monitored. Using this approach, they found no change in the sex ratio of S. glaseri with exposure time in a sand column assay, and we similarly found no change in the male proportion for this species over time. All three studies used the same (NC1) strain of S. glaseri. Stuart et al. (1998) varied the experimental conditions including age and numbers of nematodes, length of sand column and assay temperature, and in no case was there a change in sex ratio. We kept these experimental conditions constant, but included emergence time from the natal cadaver as a factor. Our results strengthen the conclusion of Stuart et al. (1998) that for S. glaseri strain NC1 at least, male colonisation is not a robust trait that is expressed under a wide variety of conditions. The particular circumstances under which it is expressed remain to be defined.

Similarly, we found no evidence of male colonisation by any of the other four species that we tested, including $S$. carpocapsae which was found by Grewal et al. (1993) to display male colonisation behaviour. However, as $S$. carpocapsae did not infect insects in our standard $4 \mathrm{~cm}$ sand column we instead used a $1 \mathrm{~cm}$ column for this species, which may have been too short to allow discrimination between male and female infection strategies. Steinernema feltiae was the only species that did not show male colonisation in the study by Grewal et al. (1993). On the contrary, Bohan and Hominick (1997) reported female-first colonisation by this species in timed dissections of hosts exposed on filter paper, and evidence for a female-first strategy was also reported by Renn (1998) who found very few males in housefly larvae exposed for a short period, but a much higher male proportion (0.45) with a longer exposure 
Table 5

Reported sex ratios of Steinernema spp. in experimentally infected insects.

\begin{tabular}{|c|c|c|}
\hline Species & Male proportion & Source \\
\hline Steinernema carpocapsae & $0.27-0.41$ & Danilov (1976) \\
\hline Steinernema scapterisci & $0.46(0.40-0.53)$ & Nguyen and Smart (1992) \\
\hline $\begin{array}{l}\text { Steinernema anomali, S. carpocapsae, Steinernema feltiae, } \\
\text { Steinernema glaseri, S. scapterisci }\end{array}$ & $0.58-1.0$ & Grewal et al. (1993) (Distance assay) \\
\hline S. anomali, S. carpocapsae, S. feltiae, S. glaseri, S. scapterisci & $0.38-0.42$ & Grewal et al. (1993) (Close contact) \\
\hline S. carpocapsae & 0.47 & Selvan et al. (1993) \\
\hline S. glaseri & $0.40,0.48,0.49,0.49$ and 0.54 & Stuart et al. (1998) \\
\hline Steinernema riobrave & 0.38 & Cabanillas (2003) \\
\hline S. carpocapsae & 0.33 & Mitani et al. (2004) \\
\hline
\end{tabular}

period. Rolston et al. (2006) found weak evidence for protandry in S. feltiae, but as both source (natal) and target hosts were included in the same arena it was not possible to distinguish between earlier emergence or a greater dispersal tendency of males. In our study, $S$. feltiae had one of the lowest within host male proportions of any of the test species, and extreme female bias ( $<20 \%$ males) was reported for S. feltiae in phorid flies (Scheepmaker et al., 1998). Thus, it seems that $S$. feltiae may differ to other species in having females that infect more readily than males. However, since the sex ratio is also female-biased in vitro, differential infection rates of male and female IJs cannot be the cause of a deviation from the balanced 1:1 but may accentuate it.

In our experimental infections, we recorded significant differences in sex ratio between nematodes that had emerged early and late from the groups of host cadavers in which they had developed. Sex ratios were recorded within hosts experimentally infected with early and late emergers. We found a similar trend in in-host sex ratio for S. glaseri as Lewis and Gaugler (1994): the proportion of males in experimentally infected hosts was higher in nematodes emerging on day 1 than on either day 10 (our experiments) or days 4 and 8 (Lewis and Gaugler, 1994). Interestingly, our experiments show the same trend in sex ratio (higher male proportion in early than in later emergers) in each of the three cruise foragers but not in the ambush (S. carpocapsae) or intermediate ( $S$. feltiae) forager species, supporting the contention (Lewis and Gaugler, 1994) that the relationship between emergence time and in-host sex ratio is related to foraging strategy. On the contrary, Fujimoto et al. (2007) also reported a higher male proportion in early emerged IJs of the ambush species S. carpocapsae: $51 \%$ and $45 \%$ males in worms that emerged on days 1-2 and day 7, respectively. However, we do not see the results of any of these studies as conclusive evidence for early emergence of males from the natal host. Such results may either indicate that the sex ratio of IJs emerging from the natal host changes with time, as assumed by Lewis and Gaugler (1994), or that the infection behaviour of one sex is more strongly influenced by emergence time than that of the other sex. When S. longicaudum was reared in vitro there was no difference between early and late emerging IJs in the proportion of males that developed, indicating that the higher male proportion of early emerged $S$. longicaudum in the sand column infection may represent a greater dispersal tendency or invasiveness of early versus later emerged males rather than a higher proportion of males in the early emerged cohort.

Overall infectivity of IJs (number of nematodes established per host) was also influenced by their time of emergence from the natal cadaver. Significant differences in infection rate between early and late emergers in one or both of the assay types were recorded for all species except $S$. kraussei. For S. carpocapsae and S. glaseri, nematodes harvested on day 10 invaded at a higher rate than those harvested on day 1 , while the reverse was found in S. feltiae and $S$. longicaudum. IJs that emerge early and late in the emergence time are likely to be the progeny of different parental generations. Early emerging IJs of entomopathogenic nematodes are larger than those that emerge later (Nguyen and Smart, 1995) and may differ behaviourally (Lewis and Gaugler, 1994; O'Leary et al., 1998; Ryder and Griffin, 2003; Rolston et al., 2006). There is a consistency across studies in the effect of emergence time on the infectivity of S. carpocapsae: Lewis and Gaugler (1994), Fujimoto et al. (2007) and our own study all found that nematodes emerging later (on days 4, 7 and 10, respectively, in these studies) are more highly infective than those that emerge earlier.

More female than male Steinernema spp. developed from infective juveniles in vitro as well as in experimentally infected hosts. Reports of Steinernema sex ratios when reared in vitro are rare, but Grewal et al. (1993) found a female-biased sex ratio in each of five Steinernema spp. reared en masse on lipid agar plates. Assuming that equal numbers of male and female IJs are produced, a female-biased adult sex ratio might arise from a higher failure rate of male IJs to recover (resume development) from the arrested IJ stage, or a higher death rate of males during development from IJ to adult. There was no difference in sex ratio between S. longicaudum that had or had not passed through the IJ stage, indicating that differential recovery rates of male and female IJs is not a factor in skewing the adult sex ratio. The success rate of $S$. longicaudum in developing from either type of juvenile to adult varied widely between batches (repetitions) for unknown reasons, possibly related to variation in the quality of the haemolymph which was derived from commercially produced insects. If males were less successful than females in developing to adult we would expect to find a higher proportion of males in batches with a higher success rate. However, there was no relationship between the proportion of juveniles developing to adult and the male proportion, and a female bias was seen even in batches where close to $100 \%$ of juveniles developed to adulthood. This indicates that the female bias is already present in the IJ or early developmental juvenile population. Either there is sex-biased mortality during early development (embryogenesis or early juvenile), or the primary sex ratio is female-biased.

Whatever the proximate mechanism, we propose that the female-biased sex ratio in Steinernema spp. is an evolutionary response to inbreeding within hosts. Although under most conditions it is expected that parents should invest equally in sons and daughters, resulting in a 1:1 sex ratio, as proposed by Fisher (1930), a different outcome is expected when brothers compete with each other for mates (Hamilton, 1967). Under these inbreeding conditions, termed "local mate competition", mothers should produce a higher proportion of daughters. The degree of bias depends on the degree of local mate competition, with higher inbreeding resulting in lower production of males, and this has been demonstrated in several taxa (West et al., 2005) including parasitic protozoa, where the sex ratio accurately reflects the degree of inbreeding in a population (Read et al., 1995; Nee et al., 2002). Natural selection may produce an equilibrium sex ratio for the habitat, or individuals may be able to facultatively alter prog- 
eny sex ratios in response to particular environmental conditions (Charnov, 1982). Sex determination in Steinernema is chromosomal with males being the heterogametic sex (XX female, XO male) (Poinar, 1967). Chromosomal sex determination constrains the feasible range of sex allocation strategies compared with, for example, the haplodiploidy of hymenopteran parasitoids, but does not preclude it (Godfray and Werren, 1996; West and Sheldon, 2002). Biased primary sex ratios are known in other invertebrates with chromosomal sex determination and male heterogamety, including spiders (Gunnarsson and Andersson, 1992) and crickets (Reinhold, 1996).

In Steinernema spp. there is potential for local mate competition, especially where an insect is invaded by a few IJs. In the Galleria model, an insect can readily be colonised by a single pair of nematodes. The progeny of these founders will be restricted to sib-sib mating, and males will continue to compete with close relatives for mating as long as they develop and mate within the same host. Under such conditions, we expect selection for the production of fewer males. However, worms produced from the alternate cycle, involving development to IJ, disperse and may mix with less closely related worms when they establish in a new host. Under these conditions, the more usual 1:1 sex ratio should be favoured (Fisher, 1930). A given female may produce some offspring for each developmental pathway (Poinar, 1990; Baliadi et al., 2004). If females could facultatively adjust the sex ratio of their progeny (West et al., 2005), we predict that the sex ratio should be less femalebiased in worms that pass through the IJ pathway (which are more likely to out-breed) than in those which do not develop to IJ but remain in the host and compete with their brothers. We did not attempt to assess the sex ratio of nematodes developing within the host beyond the first generation, due to the very large numbers and the potential for members of succeeding generations to overlap in time. As the sex ratio in S. longicaudum developing in vitro was similar whether or not they went through the IJ stage, we have no evidence that females facultatively adjust their offspring sex ratio depending on conditions. However, our experiments were not specifically designed to test facultative sex ratio adjustment.

Assuming that females do not facultatively adjust their offspring sex ratio, we suggest that the observed slight female bias in Steinernema represents the population optimal sex ratio, the result of a trade-off between fitness gains within the natal cadaver, where local mate competition favours the production of daughters, and in the dispersing generation, where outbreeding favours more equal production of sons and daughters.

\section{Acknowledgements}

The research was funded by a Libyan Government Scholarship to M. Alsaiyah, an Irish Research Council for Science and Technology (IRCSET) Postdoctoral Fellowship to L. Ebssa, and the Science Foundation Ireland (Grant number 05/RFP/EEB0009).

\section{References}

Baliadi, Y., Yoshiga, T., Kondo, E., 2004. Infectivity and post-infection development of infective juveniles originating via Endotokia matricida in entomopathogenic nematodes. Appl. Entomol. Zool. 39, 61-69.

Bohan, D.A. Hominick, W.M. 1997. Sex and the dynamics of infection in the entomopathogenic nematode Steinernema feltiae. J. Helminthol. 71, 197-201.

Boissier, J., Mone, H., 2000. Experimental observations on the sex ratio of adult Schistosoma mansoni, with comments natural male bias. Parasitology 121, 379383.

Cabanillas, H.E., 2003. Susceptibility of the boll weevil to Steinernema riobrave and other entomopathogenic nematodes. J. Invertebr. Pathol. 82, 188-197.

Campbell, J.F., Kaya, H.K., 2002. Variation in entomopathogenic nematode (Steinernematidae and Heterorhabditidae) infective-stage jumping behaviour. Nematology 4, 471-482.

Campbell, J.F., Lewis, E.E., Stock, S.P., Nadler, S., Kaya, H.K., 2003. Evolution of host search strategies in entomopathogenic nematodes. J. Nematol. 35, 142-145.
Charnov, E.L., 1982. The Theory of Sex Allocation. Princeton University Press, Princeton, New Jersey.

Danilov, L.G., 1976. The effect of temperature on the susceptibility of Galleria mellonella to infection by Neoaplectana carpocapsae Weiser, 1955 'agriotos' strain, and on the development of the nematode in the insect host. B. Vsesoyuznugo Nauch. 37, 17-21.

Fisher, R.A., 1930. The Genetical Theory of Natural Selection. Oxford University Press, Oxford.

Fujimoto, A., Lewis, E.E., Cobanoglu, G., Kaya, H.K., 2007. Dispersal, infectivity and sex ratio of early- or late-emerging infective juveniles of the entomopathogenic nematode Steinernema carpocapsae. J. Nematol. 39, 333-337.

Godfray, H.C.J., Werren, J.H., 1996. Recent developments in sex ratio studies. Trends Ecol. Evol. 11, A59-A63.

Grewal, P.S., Selvan, S., Lewis, E.E., Gaugler, R., 1993. Male insect-parasitic nematodes: a colonizing sex. Experientia 49, 605-608.

Griffin, C.T., O'Callaghan, K., Dix, I., 2001. A self-fertile species of Steinernema from Indonesia: further evidence of convergent evolution amongst entomopathogenic nematodes? Parasitology 122, 181-186.

Gunnarsson, B., Andersson, A., 1992. Skewed primary sex-ratio in the solitary spider Pityohyphantes phyrgianus. Evolution 46, 841-845.

Hamilton, W.D., 1967. Extraordinary sex ratios. Science 156, 477-488.

Holm, S., 1979. A simple sequentially rejective multiple test procedure. Scand. J. Stat. 6, 65-70.

Kaya, H.K., Gaugler, R., 1993. Entomopathogenic nematodes. Annu. Rev. Entomol. $38,181-206$

Kaya, H.K., Stock, S.P., 1997. Techniques in insect nematology. In: Lacey, L.A. (Ed.), Manual of Techniques in Insect Pathology. Academic Press, New York, pp. 281324

Lewis, E.E., Gaugler, R., 1994. Entomopathogenic nematode (Rhabdita: Steinernematidae) sex ratio relates to foraging strategy. J. Invertebr. Pathol. 64, 238-242.

Lewis, E.E., Campbell, J., Griffin, C., Kaya, H., Peters, A., 2006. Behavioral ecology of entomopathogenic nematodes. Biol. Contr. 38, 66-79.

Littell, R.C., Milliken, G.A., Stroup, W.W., Wolfinger, R.D., 1996. SAS System for Mixed Models, second ed. SAS Institute Inc., Cary.

Mitani, D.K., Kaya, H.K., Goodrich-Blair, H., 2004. Comparative study of the entomopathogenic nematode, Steinernema carpocapsae, reared on mutant and wild-type Xenorhabdus nematophila. Biol. Control 29, 382-391.

Mone, H., Boissier, J., 2004. Sexual biology of schistosomes. Adv. Parasitol. 57, 89189.

Morbey, Y.E., Ydenberg, R.C., 2001. Protandrous arrival timing to breeding areas: a review. Ecol. Lett. 4, 663-673.

Nadler, S.A., Bolotin, E., Stock, S.P., 2006. Phylogenetic relationships of Steinernema Travassos, 1927 (Nematoda : Cephalobina : Steinernematidae) based on nuclear, mitochondrial and morphological data. Syst. Parasitol. 63, 161-181.

Nee, S., West, S.A., Read, A.F., 2002. Inbreeding and parasite sex ratios. Proc. R. Soc. Lond. B Biol. Sci. 269, 755-760.

Nguyen, K.B., Smart, G.C., 1992. Life cycle of Steinernema scapterisci Nguyen and Smart, 1990. J. Nematol. 24, 160-169.

Nguyen, K.B., Smart, G.C.J., 1995. Morphometrics of infective juveniles of Steinernema spp. and Heterorhabditis bacteriophora (Nemata: Rhabditida). J. Nematol 27, 206-212.

O'Leary, S.A., Stack, C.M., Chubb, M.A., Burnell, A.M., 1998. The effect of day of emergence from the insect cadaver on the behavior and environmental tolerances of infective juveniles of the entomopathogenic nematode Heterorhabditis megidis (strain UK211). J. Parasitol. 84, 665-672.

Poinar Jr., G.O., 1967. Description and taxonomic position of the DD-136 nematode (Steinernematidae, Rhabditoidea) and its relationship to Neoaplectana carpocapsae Weiser. Proc. Helminthol. Soc. Wash. 34, 199-209.

Poinar Jr., G.O., 1990. Biology and taxonomy of Steinernematidae and Heterorhabditidae. In: Gaugler, R., Kaya, H. (Eds.), Entomopathogenic nematodes in biological control. CRC Press, Boca Raton, FLA, pp. 23-61.

Poulin, R., 1997. Population abundance and sex ratio in dioecious helminth parasites. Oecologia $111,375-380$

Read, A.F., Anwar, M., Shutler, D., Nee, S., 1995. Sex allocation and populationstructure in malaria and related parasitic protozoa. Proc. R. Soc. B 260, 359-363.

Reinhold, K., 1996. Biased primary sex ratio in the bushcricket Poecilimon veluchianus, an insect with sex chromosomes. Behav. Ecol. Sociobiol. 39, 189-194.

Renn, N., 1998. Routes of penetration of the entomopathogenic nematode Steinernema feltiae attacking larval and adult houseflies (Musca domestica). J. Invertebr. Pathol. 72, 281-287.

Roche, M., Patrzek, D., 1966. Female to male ratio (Fmr) in hookworm. J. Parasitol. 52, 117-121.

Rolston, A.N., Griffin, C.T., Downes, M.J., 2006. Emergence and dispersal patterns of two isolates of the entomopathogenic nematode Steinernema feltiae. J. Nematol. $38,221-228$

Ryder, J.J., Griffin, C.T., 2003. Phased infectivity in Heterorhabditis megidis: the effects of infection density in the parental host and filial generation. Int. J. Parasitol. 33, 1013-1018.

San-Blas, E., Gowen, S.R., Pembroke, B., 2008. Steinernema feltiae: ammonia triggers the emergence of their infective juveniles. Exp. Parasitol. 119, 180-185.

SAS Institute Inc., 2004. SAS/STAT 9.1 User's Guide. SAS Institute Inc., Cary.

Scheepmaker, J.W.A., Geels, F.P., Griensven, L.J.L.D., Van Smits, P.H., 1998. Susceptibility of larvae of the mushroom fly Megaselia halterata to the entomopathogenic nematode Steinernema feltiae in bioassays. BioControl 43, 201-214. 
Selvan, S., Campbell, J.F., Gaugler, R., 1993. Density-dependent effects on entomopathogenic nematodes (Heterorhabditidae and Steinernematidae) within an insect host. J. Invertebr. Pathol. 62, 278-284.

Spiridonov, S.E., Reid, A.P., Podrucka, K., Subbotin, S.A., Moens, M., 2004 Phylogenetic relationships within the genus Steinernema (Nematoda: Rhabditida) as inferred from analyses of sequences of ITS1-5.8S-ITS2 region of the rDNA and morphological features. Nematology 6, 547-566.

Stien, A., Dallimer, M., Irvine, R.J., Halvorsen, O., Langvatn, R., Albon, S.D., Dallas, J.F., 2005. Sex ratio variation in gastrointestinal nematodes of Svalbard reindeer: density dependence and implications for estimates of species composition Parasitology 130, 99-107.

Stock, S.P., 2005. Insect-parasitic nematodes: From lab curiosities to model organisms. J. Invertebr. Pathol. 89, 57-66.
Stuart, R.J., Abu Hatab, M., Gaugler, R., 1998. Sex ratio and the infection process in entomopathogenic nematodes: Are males the colonizing sex? J. Invertebr. Pathol. 72, 288-295.

Wang, J., Bedding, R.A., 1996. Population development of Heterorhabditis bacteriophora and Steinernema carpocapsae in larvae of Galleria mellonella. Fundam. appl. Nematol. 19, 363-367.

West, S.A., Sheldon, B.C., 2002. Constraints in the evolution of sex ratio adjustment. Science 295, 1685-1688.

West, S.A., Shuker, D.M., Sheldon, B.C., 2005. Sex-ratio adjustment when relatives interact: a test of constraints on adaptation. Evolution 59, 1211-1228.

Woodring J.L. Kaya, H.K. 1988. Steinernematid and Heterorhabditid Nematodes: A Handbook of Techniques. Arkansas Agricultural Experimental Station, Fayetteville. Zar, J.H., 1999. Biostatistical Analysis, fourth ed. Prentice Hall, New Jersey. 